\title{
Delivery and pregnancy outcome in women with bowel resection for deep endometriosis: a retrospective cohort study
}

\author{
Silvia Baggio ${ }^{1}$ Paola Pomini ${ }^{1}$ - Alessandro Zecchin ${ }^{1} \cdot$ Simone Garzon $^{1} \cdot$ Cecilia Bonin $^{1}$. \\ Lorenza Santi $^{2} \cdot$ Anna Festi $^{1} \cdot$ Massimo Piergiuseppe Franchi $^{1}$
}

Received: 25 April 2015 / Accepted: 9 June 2015 /Published online: 20 June 2015

(C) Springer-Verlag Berlin Heidelberg 2015

\begin{abstract}
Endometriosis affects women in reproductive age and can involve bowel in 6-12\% of the patients. In case of bowel occlusion or deep pain, radical laparoscopic endometriosic surgery associated with bowel resection is recommended. The purpose of this study was to analyze the conception rate, the obstetric complications, and the pregnancy outcome. This is a retrospective study; we investigated 51 patients with deep endometriosis who underwent surgical treatment with bowel resection during the period between 2000 and 2007. Among the 30 patients who gave birth to at least one live child after surgery, we considered only the first pregnancy following bowel resection and we investigated the incidence of pregnancy disorders, the gestational age at delivery, the baby birth weight, and the complications related to the different ways of delivery. We compared the results with a control group of 93 patients with no previous abdominal surgery. The whole group of 51 patients tried to conceive after surgery, and 30 women had at least one pregnancy with the birth of an alive baby. Considering only the first pregnancies after surgery, 6 (20\%) experienced gestational hypertensive disorders, 3 (10\%) had placenta previa, 6 (20\%) had preterm birth ( $<37$ weeks), and 1 patient (3.3\%) gestational diabetes. In this group, the average newborn weight was $3000 \pm 545 \mathrm{~g}$. Compared with the control group, women with previous bowel resection for deep endometriosis had a higher risk of
\end{abstract}

Silvia Baggio

silvia.baggio1@gmail.com

1 Department of Obstetrics and Gynaecology, University of Verona, Piazzale L.A. Scuro 10, 37134 Verona, Italy

2 Department of Endocrinology, University of Verona, Piazzale L.A. Scuro 10, 37134 Verona, Italy hypertensive disorders $(p<0.05)$, placenta previa $(p<0.05)$, and lower newborn weight $(p<0.05)$, while the association with preterm birth and gestational diabetes was not statistically significant. These patients experience 12 vaginal deliveries (40\%) and 18 caesarean sections (60\%). Comparing with the caesarean rate in the control group (29.03\%), the incidence of caesarean section in the study population was substantially higher $(p<0.01)$ with $33.3 \%$ of the sections performed because of previous bowel surgery. No differences in severe complication rates were observed between vaginal and caesarean deliveries (ns). Complete removal of endometriosis with bowel segmental resection seems to improve the pregnancy rate, but in this group, there is an increased incidence of hypertensive disorders, placenta previa, and lower newborn weight. Despite the small number of patients, we do not observe more complications in the vaginal group than in the caesarean group, so we hypothesize the previous radical surgery should not influence the way of delivery.

Keywords Endometriosis · Bowel resection · Pregnancy

\section{Introduction}

Endometriosis is characterized by the presence of the endometrial glands and stroma outside the uterine cavity. It primarily affects women of fertile age and represents a relevant clinical issue as it causes severe abdominal pain $[1,2]$ and infertility $[2,3]$.

Endometriosis is classified depending on location, extent and depth of implants, presence and severity of adhesions, and presence and size of ovarian endometriomas.

The incidence of bowel implants among women with endometriosis is between 6 and $12 \%$ [4-7]. The most affected sites are the rectum and recto-sigmoid junction, which account 
for up to $93 \%$ [8-10] of all intestinal endometriosis lesions. When this kind of lesion is associated with deep pain, stenosis, or massive bowel involvement, the recommended approach is the complete excision of deep endometriosis with bowel resection [11]. In these last years, many authors have reported different surgical procedures to remove endometriosis nodules from bowel like the shaving technique that consists in the excision of nodule after its complete resection from the rectum without resection [12]. Bowel endometriosis removal let the patient have a reliable and persistent relief of pain symptoms and improvement of quality of life [13-22] and leads to a better fertility and pregnancy rate [23].

Considering the young age of women who undergo this radical surgery, and the related fertility improvement, the aims of our study were to analyze the obstetric complications and the outcome of the pregnancies conceived after surgery and to evaluate if there is a recommended way of delivery conscious of short- and long-term complications related to a bowel segmental resection.

\section{Methods}

From July 1996 to February 2007, 329 infertile women with severe endometriosis underwent laparoscopic surgery treatment at the Gynecology and Obstetrics Department of the Ospedale Sacro Cuore (Negrar, Italy).

In our study, we analyze only the 77 patients who had a colorectal segmental resection. The indications for radical surgery with bowel resection were severe pelvic pain refractory to medical treatments and/or severe bowel stenosis caused by endometriosis implants.

In our Unit, in case of deep endometriosis with muscularis involvement, the treatment of choice is bowel segmental resection. The shaving technique is performed if the endometriotic nodule involves only the serosa.

In all cases, surgery was performed by laparoscopy. Each procedure was performed using a 10-mm laparoscope in the umbilical position and three 5-mm trocars. After an accurate check of the pelvic and abdominal organs, adnexal adhesions, when present, were sectioned with micro-scissors. Where endometriomas were present, steeping and temporary ovarian suspension was performed. Complete excision of all visible endometriosis lesions from healthy tissue was obtained using 5-mm bipolar scissors according to the technique described by Redwine [24]. Pre- and post-operative management has already been reported in previous studies $[21,25,26]$. The intestinal surgery was performed by a colorectal surgeon with a $\mathrm{T}-\mathrm{T}$ colorectal anastomosis. All women were clinically evaluated at 1 month, 6 months 1 year up to 4 years after surgery, and all findings were recorded in a specific database.

In this retrospective study, data about history, surgery, complications, and follow-up were obtained from database and medical records, while data concerning obstetric outcomes were updated contacting the 77 patients between July and August 2013.

Only 51 of 77 patients who underwent bowel resection were considered in our study; 26 patients were not contactable. Among the patients who conceived after surgery, we retrieved data from medical records about conception, complications during pregnancy, gestational age at delivery, birth weight, way of delivery, indications (caesarean section), and possible complications. Previous caesarean delivery was considered an obstetric indication. We collected the same obstetric data from a population without endometriosis who delivered in January and February 2007 in our Unit (control group) to compare the incidence of obstetric complications and the way of delivery in the two groups. The control group included 92 women with good health, no previous caesarean section or bowel surgery, regular menstrual cycle, no dysmenorrhea, no dyspareunia, no dyschezia, and normal gynecological evaluation before the conception. Subjects with medical conditions, previous bowel surgery, or suspicion of endometriosis were excluded.

\section{Statistics}

All statistical analysis was carried out with a SPSS 21.0 software. Continuous variables were expressed as arithmetic mean $+\mathrm{SD}$; in case of asymmetric quantitative variables, the indicators were associated with the median, maximum, and minimal values. Categorical variables were expressed as distributions of absolute or relative frequencies. The distribution of conceptions and deliveries during follow-up was studied with the Kaplan-Meier curves. The chi-square test and Fisher exact test were used to compare data obtained by cross tabs. Statistical significance was declared at $p<0.05$.

\section{Results}

Demographic data were similar in the case and control group population; none had previous caesarean section, and they did not differ in age and gestational age at delivery (Table 1).

\section{Pregnancies}

After surgery, all patients tried to conceive and 38 (70.37\%) obtained at least one pregnancy with a total of 68 pregnancies. Spontaneous miscarriage was observed in 19/68 (23.53\%) and ectopic pregnancy in 2/68 (2.94\%). The remaining $47 /$ $68(73.53 \%)$ had ongoing pregnancies with a live child delivery.

In summary, 30 patients had at least one ongoing pregnancy with delivery, in particular, 14/30 (46.6\%) had one 
Table 1 Demographic characteristics of case and control patients

\begin{tabular}{llll}
\hline & Case & Control & $p$ \\
\hline Number of patients & 51 & 93 & \\
Age (years) & $30.9 \pm 3.3$ & $30.7 \pm 4.0$ & N.S. \\
Gestational age (w) & $38.1 \pm 2.2$ & $38.3 \pm 3.3$ & N.S. \\
Hypertension/preeclampsia & $20 \%$ & $5.4 \%$ & $<0.05$ \\
Abnormal placentation & $10 \%$ & $2.2 \%$ & $<0.05$ \\
Neonatal weight (g) & $3000 \pm 545$ & $3287 \pm 671$ & $<0.05$ \\
\hline
\end{tabular}

NS no significative, $W$ weeks

pregnancy, 15/30 (50\%) had two pregnancies, and one patient $(3.3 \%)$ had 3 ongoing pregnancies.

Before radical surgery with bowel resection, only $2 / 51$ (3.9\%) patients had an ongoing pregnancy with a live child delivery, even if $32 / 51(62.7 \%)$ were trying to conceive for more than 1 year, while after surgery 30/51 (58.8\%). This difference is statistically significant $(p<0.001)$.

\section{Conception}

Most of the ongoing pregnancies with delivery were obtained spontaneously (71 \%), while 14/47 (29\%) were obtained with in vitro fertilization (IVF). The mean age at the first conception was 30.1 years (d.s. 3.2). Spontaneous pregnancies had a mean interval from surgery of 13.8 months (d.s. 14.1) and a median of 9 months, with a minimum interval of 0 month and a maximum of 53 months. Pregnancies obtained with IVF had a mean interval of 26.8 months (d.s. 21.4) and a median of 22 months, with a minimum interval of 6 and a maximum of 85 months.

\section{Gestational age and fetal growth}

We considered only the first pregnancy with the birth of a live child. The mean gestational age at delivery was 38.10 weeks (d.s. 2.25), with a median of 38 weeks, a minimum gestational age of 33 weeks, and a maximum of 42 .

Six of thirty pregnancies $(20 \%)$ ended with a preterm delivery (before 37 weeks), with a mean gestational age of 34.62 weeks (d.s. 1.21). Among these pregnancies, 1 ended because of a preterm labor with consequent vaginal delivery during the 36th week without any complications, while 5 had caesarean delivery with a mean gestational age of 34.40 weeks (d.s. 1.14). The indications of these caesarean sections were different; 2 were performed at 35 and 36 weeks after the diagnosis of labor because of the previous bowel resection, to protect the anastomosis, 1 for breech presentation and premature rupture of membranes at 34 weeks, 1 for severe IUGR $(<5 \%$ percentile) and Doppler velocimetry alterations at 34 weeks, and 1 for twin pregnancy and preterm labor at 33 weeks of gestation. Excluding the twin newborns, the mean weight at birth was $3000 \mathrm{~g}$ (d.s. 545) with a median of $3100 \mathrm{~g}$, a minimum weight of $1900 \mathrm{~g}$, and a maximum of $3880 \mathrm{~g}$.

In the control group the mean gestational age at the delivery was 38.3 weeks (d.s. 3.3), with a median of 37.9 weeks, a minimum gestational age of 27 weeks and a maximum of 41.6 weeks.

Thirteen of 93 pregnancies (14\%) ended with a preterm delivery (before 37 weeks), with a mean gestational age of 33.2 weeks (d.s. 3.8). The newborn mean weight at birth was $3287 \mathrm{~g}$ (d.s. 671) with a median of $3365 \mathrm{~g}$, a minimum weight of $540 \mathrm{~g}$, and a maximum of $4300 \mathrm{~g}$.

\section{Pregnancy complications}

In the case group, $6 / 30$ pregnancies $(20 \%)$ were complicated by hypertensive disorders (gestational hypertension and preeclampsia, with one case of severe eclampsia). Only one pregnancy $(3 \%)$ was complicated by diabetes mellitus. The abnormal placentation complicated 3 pregnancies $(10 \%)$; in particular, 2 pregnancies presented placenta previa (all obtained with IVF) and one placental flow alterations.

In the control group, $5 / 93$ pregnancies $(5.4 \%)$ were complicated by hypertensive disorders while 10/93 (10.8\%) were complicated by diabetes mellitus. Abnormal placentation complicated 2 pregnancies $(2.2 \%)$; in particular, 1 pregnancy presented placenta previa $(1.1 \%)$ and $1(1.1 \%)$ placental flow alterations.

\section{Delivery}

Among the 30 pregnancies in the case group, there were 12 vaginal deliveries (40\%) and 18 caesarean deliveries (60\%). No significant difference was observed in the two groups concerning the interval time between surgery and delivery ( $p=0.9$ ). Dividing the 18 caesarean deliveries into two groups based on the indications, $10(55.6 \%)$ had an obstetric indication, while 8 (44.4\%) were performed to protect the colonrectal anastomosis, to prevent bowel perforation in this minor resistance point, in particular during labor expulsive stage when there is the maximum increase of abdominal pressure.

In the study population, vaginal deliveries were mainly complicated by minor injuries: first or second degree perineal laceration (50\%), episiotomy (16.6\%), and manual removal of placenta $(8.3 \%)$. Only one vaginal delivery $(8.3 \%)$, 10 months after surgery, was severely complicated with a wide laceration of the cervix, vagina, and rectum at the level of the suture of the previous bowel resection. The patient had a reconstructive surgery, without long-term complications.

Regarding caesarean deliveries, only two were severely complicated $(11.1 \%)$. The first case, 33 months after the radical surgery, presented a severe adhesion syndrome and developed severe intra-operative uterine bleeding and was admitted to ICU. In the second case, 24 months after bowel surgery, the 
diffuse adhesions between the uterus and bladder determined a large full-thickness bladder incidental laceration with reconstructive urological surgery. The patient developed urine retention with intermittent self-catheterization.

In the control group, there were $27 / 93$ (29.03\%) caesarean sections and 66/93 (70.07\%) vaginal deliveries. The complications during vaginal deliveries were first or second degree perineal laceration $(45.4 \%)$, episiotomy $(18.2 \%)$, and tracheloraffia $(1.5 \%)$. There were no urinary tract injuries during the caesarean sections in the control group, but 2 patients $(7.4 \%)$ had severe intra-operative bleeding with necessity of blood transfusion in one case (3.7\%).

\section{Discussion}

Many studies have demonstrated the close relationship between endometriosis and infertility and the improvement of the pregnancy rate and pelvic pain after radical surgery $[16$, $18,19,23,27,28]$. In particular, among women with bowel endometriosis, articles in literature confirm that the postoperative fertility rate is improved if segmental bowel resection is performed (Table 2).

Stepniewska et al. [23] reported a cumulative pregnancy rate of $35 \%$ after bowel surgery in infertile women; Darai [27] reported 5 pregnancies in 12 infertile patients (42\%), and Kavallaris [16] reported 8 pregnancies in 15 infertile women (47\%) with previous bowel surgery. Our study shows a statistical significant improvement of pregnancy rate in infertile woman, after bowel surgery for endometriosis with the highest pregnancy rate, $70.4 \%$ after surgery versus $3.9 \%$ before $(p<0.01)$.

The cumulative pregnancy rate is $50 \%$ at 9 months for spontaneous conceptions and at 16 months for conceptions obtained with artificial reproductive techniques (ART), which is comparable to the results obtained by other authors [29]. This confirms that the maximum fertility rate is immediately after surgery considering both spontaneous and ART pregnancies (Fig. 1).

Donnez et al. reported an important increase of pregnancy rate after shaving technique too (57\%) [12]. Whether one technique is better than the other or not in terms of pain relief, fertility, and short- and long-term complications is still controversial, and it often depends on the surgeon and its experience. The high pregnancy rate observed after surgery both with bowel resection and shaving approach suggests that the increase in fertility is more likely to be related to the removal of the endometriotic disease rather than a specific surgical technique.

Although fertility after bowel surgery has been wide studied, outcome and way of delivery of the pregnancies obtained after this surgery have only been considered in few papers.
In a study including more than 1.4 million singleton births, Stephansson et al. [30] observed that endometriosis was associated with preterm birth, preeclampsia, and placental complications.

In our study, the mean gestational age at delivery was 38.16 weeks and $20 \%$ of deliveries were before 37 weeks. Considering that the rate of preterm delivery in the general population is $10 \%$, and in the control group $14 \%$, we observed a significant increase in the risk of preterm birth in the case population $(p=0.005)$. Moreover, in women with previous bowel surgery, the newborn weight at birth was significantly lower than the control group ( $p=0.04)$.

Another important finding is the incidence of hypertensive disorders during pregnancy in our population $(20 \%)$ which, compared with the rate of hypertension/preeclampsia in the control group population (5.4\%), confirms that women operated for deep endometriosis had a higher risk to develop this disorder $(p=0.024)$. This is in contrast with the results reported by Brosen et al. [31], who showed a decrease in risk of preeclampsia in women with endometriosis.

Vercellini et al. [32] in his study did not detect any particular findings with regard to the incidence of hypertension, preeclampsia, preterm birth, and abruption placenta, but he found an incidence of $3.7 \%$ of placenta previa in women with endometriosis, more than 10 times the figure of $0.3 \%$ reported in the general population.

Our study confirms this increased risk of placenta previa with an incidence of $6.6 \%$ in the case population and only $1.1 \%$ in the control group $(p=0.045)$. This risk in women with endometriosis is probably related to abnormal endometrial receptivity and a subsequent alteration in placentation, but further data are needed.

No significant differences were observed in the incidence of diabetes $(p=0.19)$ between the case and the control groups.

Besides the obstetric outcome, there is another fundamental point to analyze regarding women who undergo bowel resection for deep endometriosis, the way of delivery.

There are no studies in literature that focus on this issue, and there is no common consensus. In our study, $60 \%$ of deliveries were caesarean sections and $33.3 \%$ were performed because of previous bowel surgery. In control group, the caesarean rate was clearly lower, $29.3 \%$. Refusing to perform an intestinal resection in a symptomatic patient who desires a child, persuaded that pregnancy hormones would solve the situation, is not the way to avoid caesarean sections, and sometimes, it could be dangerous. There are studies in literature that show the existence of a specific entity of deep endometriosis reacting differently to the hormonal environment of a pregnancy and responsible of severe bowel complications during the third trimester of pregnancy, like perforations or intestinal occlusions [33]. To find if there is a safer way to deliver after bowel surgery, in this pilot study, we decided to compare complication incidence after vaginal and caesarean 
Table 2 Studies regarding the fertility outcome after bowel resection for intestinal endometriosis, compared with the conducted study

\begin{tabular}{|c|c|c|c|c|c|c|c|}
\hline Study & No. of patients & $\begin{array}{l}\text { No. of infertile } \\
\text { patients } \\
\text { searching } \\
\text { offspring }\end{array}$ & $\begin{array}{l}\text { Obtained } \\
\text { pregnancies }\end{array}$ & $\begin{array}{l}\text { Length of } \\
\text { follow-up } \\
\text { after surgery }\end{array}$ & Surgical treatment & $\begin{array}{l}\text { Other } \\
\text { considerations }\end{array}$ & Note \\
\hline Darai 2005 & $\begin{array}{l}34 \text { (colorectal } \\
\text { endometriosis) }\end{array}$ & 12 & $5 \quad(\mathrm{PR}=42 \%)$ & $\begin{array}{l}24 \text { months } \\
\text { (mean FU), } \\
\text { min } 6 \text { months }\end{array}$ & $\begin{array}{l}\text { LPS segmental } \\
\text { intestinal } \\
\text { resection }\end{array}$ & $\begin{array}{l}\text { PR in the } \\
\text { whole } \\
\text { group }= \\
45 \% \\
(10 / 22)\end{array}$ & $\begin{array}{l}9 \text { spontaneous } \\
\text { pregnancies, } 3 \text { with } \\
\text { IVF }\end{array}$ \\
\hline $\begin{array}{l}\text { Thomassin } \\
2004\end{array}$ & $\begin{array}{l}27 \text { (colorectal } \\
\text { endometriosis) }\end{array}$ & 8 & 2 & $\begin{array}{l}15 \text { months } \\
\text { (mean FU), range } \\
\text { 3-22 months }\end{array}$ & $\begin{array}{l}\text { Segmental } \\
\text { intestinal } \\
\text { resection: } 25 \\
\text { LPS, 2 LPT }\end{array}$ & $\begin{array}{l}4 \text { pregnancies } \\
\text { in the whole } \\
\text { group } \\
(4 / 27)\end{array}$ & $\begin{array}{l}\text { All spontaneous } \\
\text { pregnancies }\end{array}$ \\
\hline $\begin{array}{r}\text { Fleisch } \\
2005\end{array}$ & $\begin{array}{l}23 \text { (infiltrative } \\
\text { endometriosis } \\
\text { of bowel } \\
\text { or bladder) }\end{array}$ & 4 & 2 & $45 \pm 18$ months & $\begin{array}{l}\text { LPT, } 22 \text { segmental } \\
\text { resections }\end{array}$ & $\begin{array}{l}4 \text { pregnancies } \\
\text { in the whole } \\
\text { group } \\
(4 / 17)\end{array}$ & $\begin{array}{l}\text { Only a pregnancy } \\
\text { obtained with IVF, } \\
\text { other } 3 \text { were } \\
\text { spontaneous }\end{array}$ \\
\hline $\begin{array}{l}\text { Kavallaris } \\
2003\end{array}$ & $\begin{array}{l}50 \\
\quad \text { (rectal } \\
\quad \text { endometriosis) }\end{array}$ & $\begin{array}{l}17 \text { searching } \\
\text { offspring } \\
\text { (38 infertile } \\
\text { PZ) }\end{array}$ & 8 & 32 months & $\begin{array}{l}\text { LPS, segmental } \\
\text { intestinal } \\
\text { resection }\end{array}$ & $\begin{array}{l}3 \text { early } \\
\text { abortion, } \\
\text { non-EP }\end{array}$ & $\begin{array}{l}2 \text { pregnancies after } \\
\text { IVF, others were } \\
\text { spontaneous }\end{array}$ \\
\hline $\begin{array}{c}\text { Possover } \\
2000\end{array}$ & $\begin{array}{l}34 \text { (segmental } \\
\text { intestinal } \\
\text { resection) }\end{array}$ & 15 & 8 & $\begin{array}{l}16 \text { months } \\
\text { (mean FU) }\end{array}$ & $\begin{array}{l}\text { Via vaginal } \\
\text { resection } \\
\text { laparoscopically } \\
\text { assisted }\end{array}$ & $\begin{array}{l}\text { All patients } \\
\text { with } \\
\text { primary } \\
\text { infertility }\end{array}$ & \\
\hline $\begin{array}{l}\text { Stepniewska } \\
2009\end{array}$ & $\begin{array}{l}60 \text { (bowel } \\
\text { endometriosis) }\end{array}$ & 48 & $17 \quad(\mathrm{PR}=35 \%)$ & $\begin{array}{l}26.9 \text { months } \\
\quad(\text { mean FU) }\end{array}$ & $\begin{array}{l}\text { LPS, segmental } \\
\text { intestinal } \\
\text { resection }\end{array}$ & $\begin{array}{l}\text { PR compared } \\
\text { with no } \\
\text { resection } \\
\text { surgery }\end{array}$ & $\begin{array}{l}\text { PR improved by } \\
\text { intestinal resection } \\
\text { when there are } \\
\text { lesions }\end{array}$ \\
\hline Our study & $\begin{array}{l}54 \text { (bowel } \\
\text { endometriosis) }\end{array}$ & 54 & 33 & $\begin{array}{l}\text { Mean } 113 \text { months } \\
\text { (d.s. 16), range } \\
68-153, \text { median } \\
113\end{array}$ & $\begin{array}{l}\text { LPS, segmental } \\
\text { intestinal } \\
\text { resection }\end{array}$ & $\begin{array}{l}50 \text { pregnancies } \\
\text { with } \\
\text { newborns }\end{array}$ & $\begin{array}{l}36 \text { spontaneous } \\
\quad(71.43 \%), 14 \text { with } \\
\text { IVF e IUI }(28.57 \%)\end{array}$ \\
\hline
\end{tabular}

delivery in the two groups. In the case population, vaginal deliveries were mainly complicated by minor injuries; only one vaginal delivery $(8.3 \%)$ was severely complicated with

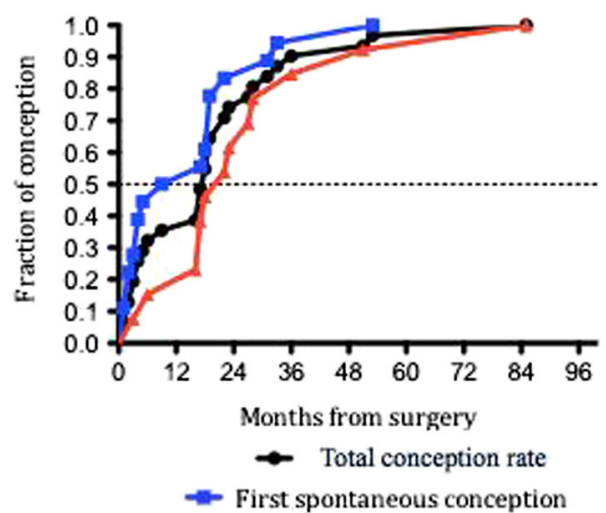

- First conception with reproductive technique

Fig. 1 Time distribution (months from surgery) of the first pregnancy conceptions (Kaplan-Meier). Dashed line shows the $50 \%$ of conceptions after surgery. Black: total conceptions; blue: spontaneous conceptions; red: conceptions with reproductive technique a laceration of the rectum at the level of the suture of the previous bowel resection. Among the patients who underwent caesarean section, two had severe complications (11.1\%). In conclusion, our results show no difference in complications in women with bowel endometriosis who had a vaginal birth or a caesarean section $(p=0.8)$ and no differences in complications during caesarean or vaginal delivery comparing the case and control group $(p=0.09)$. More studies with larger population are needed to confirm these preliminary results.

In literature, we found some studies that analyze the way of delivery in women who underwent ileal pouch-anal anastomosis (IPAA) for chronic ulcerative colitis. The condition of these populations and the case group is similar; they are young women looking for pregnancy, who undergo abdominal surgery and intestine resection, with consequent risk of massive adhesions and the presence of a rectal/anal point of minor resistance, dangerous with the increased abdominal pressure during delivery.

Many retrospective studies have documented that the pouch function in women with IPAA during labor and 
delivery is well preserved. Hanloser et al. [34] used the Mayo Clinic database to evaluate delivery outcomes in women after IPAA, and they found no increases in pouch complications or functional problems in those who had vaginal birth rather than caesarean section. Among the women who had vaginal delivery before and after IPAA, no differences were found concerning the duration of labor or labor complication rates pre-IPAA versus post-IPAA in the same women. Studies by Juhasz et al. [35] and Ravid et al. [36] echo the same findings.

A 2005 report from Cleveland Clinic [37] concluded that recommendation for vaginal delivery should be cautious because it found a major incidence of sphincter defects in women with an IPAA who had a vaginal delivery versus those who had a caesarean section. A 2007 review of literature confirmed that vaginal delivery places all women at risk of sphincter injury (in the general population, the incidence is $0.3 \%$ ) in particular if compared with caesarean section, but it underlined that there is no evidence to suggest that this risk is greater in women with an IPAA [38].

The review of literature regarding IPAA confirms the results of our study; there is no contraindication to vaginal delivery for women who undergo bowel resection for deep endometriosis as ACOG recommended [39]. In these women, the way of delivery should be chosen considering only obstetrical concerns. In fact, the Committee of Obstetric Practice believes that in the absence of maternal or fetal indications for caesarean delivery, a plan for vaginal delivery is safe and appropriate with a shorter maternal hospitalization, lower infection rates, fewer anesthetic complications, and lower risk of respiratory problems for the infant. Moreover, the presence of endometriosis increases the risk of surgery complications during caesarean section, in particular lower urinary tract injury, often related to bladder adhesions high up on the lower uterine segment. Previous caesarean section and severe endometriosis with bladder-uterine localizations are the major risk factors for bladder injury during caesarean section [40].

To reduce the incidence of the worst complications during labor and vaginal delivery in women with previous bowel resection, we think it would be interesting to study if there is a safe time interval between surgery and delivery. In our study, the rectum laceration during labor was in the patient with the smallest interval between surgery and delivery (10 months), maybe too short for a correct healing. On the other hand, it is well known that the best period to conceive is the closest to surgery, so waiting too much could be unfavorable.

Further studies may be necessary to evaluate if there is a safe interval of time to wait after bowel resection to conceive without an important reduction of the pregnancy rate.

Compliance with ethical standards All procedures followed were in accordance with the ethical standards of the responsible committee on human experimentation (institutional and national) and with the 1964
Helsinki Declaration and its later amendments or comparable ethical standards.

Conflict of interest The authors declare that they have no competing interests.

Informed consent Informed consent was obtained from all individual participants included in the study.

\section{References}

1. Koninckx PR, Meuleman C, Demeyere S, Lesaffre E, Cornillie FJ (1991) Suggestive evidence that pelvic endometriosis is a progressive disease, whereas deeply infiltrating endometriosis is associated with pelvic pain. Fertil Steril 55:759-65

2. Fauconnier A, Chapron C, Dubuisson JB, Vieira M, Dousset B, Bréart G (2002) Relation between pain symptoms and the anatomic location of deep infiltrating endometriosis. Fertil Steril 78:719-26

3. Pouly JL, Drolet J, Canis M, Boughazine S, Mage G, Bruhat MA et al (1996) Laparoscopic treatment of symptomatic endometriosis. Hum Reprod 11(Suppl 3):67-88

4. Macafee CH, Greer HL (1960) Intestinal endometriosis. A report of 29 cases and a survey of the literature. J Obstet Gynaecol Br Emp 67:539-55

5. Weed JC, Ray JE (1987) Endometriosis of the bowel. Obstet Gynecol 69:727-30

6. Jerby BL, Kessler H, Falcone T, Milsom JW (1999) Laparoscopic management of colorectal endometriosis. Surg Endosc 13:1125-8

7. Chapron C, Fauconnier A, Dubuisson JB, Barakat H, Vieira M, Bréart G (2003) Deep infiltrating endometriosis: relation between severity of dysmenorrhoea and extent of disease. Hum Reprod 18: $760-6$

8. Coronado C, Franklin RR, Lotze EC, Bailey HR, Valdés CT (1990) Surgical treatment of symptomatic colorectal endometriosis. Fertil Steril 53:411-6

9. Bailey HR, Ott MT, Hartendorp P (1994) Aggressive surgical management for advanced colorectal endometriosis. Dis Colon Rectum 37:747-53

10. Tran KT, Kuijpers HC, Willemsen WN, Bulten H (1996) Surgical treatment of symptomatic rectosigmoid endometriosis. Eur J Surg 162:139-41

11. Wattiez A, Puga M, Albornoz J, Faller E (2013) Surgical strategy in endometriosis. Best Pract Res Clin Obstet Gynaecol 27:381-92

12. Donnez J, Squifflet J (2010) Complications, pregnancy and recurrence in a prospective series of 500 patients operated on by the shaving technique for deep rectovaginal endometriotic nodules. Hum Reprod 25:1949-1958

13. Canis M, Botchorishvili R, Slim K, Pezet D, Pouly JL, Wattiez A et al (1996) [Bowel endometriosis. Eight cases of colorectal resection]. J Gynecol Obstet Biol Reprod (Paris) 25:699-709

14. Duepree HJ, Senagore AJ, Delaney CP, Marcello PW, Brady KM, Falcone T (2002) Laparoscopic resection of deep pelvic endometriosis with rectosigmoid involvement. J Am Coll Surg 195:754-8

15. Abbott JA, Hawe J, Clayton RD, Garry R (2003) The effects and effectiveness of laparoscopic excision of endometriosis: a prospective study with 2-5 year follow-up. Hum Reprod 18:1922-7

16. Kavallaris A, Köhler C, Kühne-Heid R, Schneider A (2003) Histopathological extent of rectal invasion by rectovaginal endometriosis. Hum Reprod 18:1323-7

17. Ford J, English J, Miles WA, Giannopoulos T (2004) Pain, quality of life and complications following the radical resection of rectovaginal endometriosis. BJOG 111:353-6 
18. Thomassin I, Bazot M, Detchev R, Barranger E, Cortez A, Darai E (2004) Symptoms before and after surgical removal of colorectal endometriosis that are assessed by magnetic resonance imaging and rectal endoscopic sonography. Am J Obstet Gynecol 190:1264-71

19. Fleisch MC, Xafis D, De Bruyne F, Hucke J, Bender HG, Dall P (2005) Radical resection of invasive endometriosis with bowel or bladder involvement-long-term results. Eur J Obstet Gynecol Reprod Biol 123:224-9

20. Dubernard G, Piketty M, Rouzier R, Houry S, Bazot M, Darai E (2006) Quality of life after laparoscopic colorectal resection for endometriosis. Hum Reprod 21:1243-7

21. Landi S, Mereu L, Pontrelli G, Stepniewska A, Romano L, Tateo S et al (2008) The influence of adenomyosis in patients laparoscopically treated for deep endometriosis. J Minim Invasive Gynecol 15:566-70

22. Ferrero S, Anserini P, Abbamonte LH, Ragni N, Camerini G, Remorgida V (2009) Fertility after bowel resection for endometriosis. Fertil Steril 92:41-6

23. Stepniewska A, Pomini P, Bruni F, Mereu L, Ruffo G, Ceccaroni M et al (2009) Laparoscopic treatment of bowel endometriosis in infertile women. Hum Reprod 24:1619-25

24. Redwine DB (2004) Surgical management of endometriosis. Martin Dunitz, Taylor \& Francis, New York, USA

25. Landi S, Ceccaroni M, Perutelli A, Allodi C, Barbieri F, Fiaccavento A et al (2006) Laparoscopic nerve-sparing complete excision of deep endometriosis: is it feasible? Hum Reprod 21:774-81

26. Mereu L, Ruffo G, Landi S, Barbieri F, Zaccoletti R, Fiaccavento A et al (2007) Laparoscopic treatment of deep endometriosis with segmental colorectal resection: short-term morbidity. J Minim Invasive Gynecol 14:463-9

27. Daraï E, Marpeau O, Thomassin I, Dubernard G, Barranger E, Bazot M (2005) Fertility after laparoscopic colorectal resection for endometriosis: preliminary results. Fertil Steril 84:945-50

28. Possover M, Diebolder H, Plaul K, Schneider A (2000) Laparascopically assisted vaginal resection of rectovaginal endometriosis. Obstet Gynecol 96:304-7

29. Chapron C, Fritel X, Dubuisson JB (1999) Fertility after laparoscopic management of deep endometriosis infiltrating the uterosacral ligaments. Hum Reprod 14:329-32
30. Stephansson O, Kieler H, Granath F, Falconer H (2009) Endometriosis, assisted reproduction technology, and risk of adverse pregnancy outcome. Hum Reprod 24:2341-7

31. Brosens I, Brosens JJ, Fusi L, Al-Sabbagh M, Kuroda K, Benagiano G (2012) Risks of adverse pregnancy outcome in endometriosis. Fertil Steril 98:30-5

32. Vercellini P, Parazzini F, Pietropaolo G, Cipriani S, Frattaruolo MP, Fedele L (2012) Pregnancy outcome in women with peritoneal, ovarian and rectovaginal endometriosis: a retrospective cohort study. BJOG 119:1538-43

33. Setubal A, Sidiropoulou Z, Torgal M, Casal E (2014) Bowel complications of deep endometriosis during pregnancy or in vitro fertilization. Fertil Steril 101(2):442-6

34. Hahnloser D, Pemberton JH, Wolff BG, Larson D, Harrington J, Farouk R et al (2004) Pregnancy and delivery before and after ileal pouch-anal anastomosis for inflammatory bowel disease: immediate and long-term consequences and outcomes. Dis Colon Rectum 47:1127-35

35. Juhasz ES, Fozard B, Dozois RR, Ilstrup DM, Nelson H (1995) Ileal pouch-anal anastomosis function following childbirth. An extended evaluation. Dis Colon Rectum 38:159-65

36. Ravid A, Richard CS, Spencer LM, O'Connor BI, Kennedy ED, MacRae HM et al (2002) Pregnancy, delivery, and pouch function after ileal pouch-anal anastomosis for ulcerative colitis. Dis Colon Rectum 45:1283-8

37. Remzi FH, Gorgun E, Bast J, Schroeder T, Hammel J, Philipson E et al (2005) Vaginal delivery after ileal pouchanal anastomosis: a word of caution. Dis Colon Rectum 48: 1691-9

38. Cornish J, Tan E, Teare J, Teoh TG, Rai R, Clark SK et al (2007) A meta-analysis on the influence of inflammatory bowel disease on pregnancy. Gut 56:830-7

39. American College of Obstetricians and Gynecologists (2013) ACOG committee opinion no. 559: cesarean delivery on maternal request. Obstet Gynecol 121:904-7

40. Phipps MG, Watabe B, Clemons JL, Weitzen S, Myers DL (2005) Risk factors for bladder injury during cesarean delivery. Obstet Gynecol 105:156-60 